\title{
Presence of the RHD pseudogene and the hybrid RHD-CE-Ds gene in Brazilians with the D-negative phenotype
}

\section{A. Rodrigues ${ }^{1}$, M. Rios ${ }^{2}$, J. Pellegrino Jr. ${ }^{1}$, F.F. Costa ${ }^{1}$ and L. Castilho ${ }^{1}$}

\author{
${ }^{1}$ Hemocentro, Universidade Estadual de Campinas, \\ Campinas, SP, Brasil \\ ${ }^{2} \mathrm{New}$ York Blood Center, New York, NY, USA
}

\section{Correspondence \\ A. Rodrigues \\ Hemocentro, Unicamp \\ Rua Carlos Chagas, 480 \\ Caixa Postal 6198 \\ 13081-970 Campinas, SP \\ Brasil \\ Fax: +55-19-3289-1089 \\ E-mail: artemisr@bol.com.br \\ Research supported by FAPESP \\ (Nos. 99/03620-0 and 00/03510-0).}

Received October 19, 2001 Accepted May 7, 2002

\section{Abstract}

The molecular basis for $R H D$ pseudogene or $R H D \Psi$ is a 37-bp insertion in exon 4 of $R H D$. This insertion, found in two-thirds of Dnegative Africans, appears to introduce a stop codon at position 210. The hybrid $R H D-C E-D^{s}$, where the 3' end of exon 3 and exons 4 to 8 are derived from $R H C E$, is associated with the VS+V-phenotype, and leads to a D-negative phenotype in people of African origin. We determined whether Brazilian blood donors of heterogeneous ethnic origin had $R H D \Psi$ and $R H D-C E-D^{s}$. DNA from 206 blood donors were tested for $R H D \Psi$ by a multiplex PCR that detects $R H D, R H D \Psi$ and the $\mathrm{C}$ and $\mathrm{c}$ alleles of $R H C E$. The RHD genotype was determined by comparison of size of amplified products associated with the $R H D$ gene in both intron 4 and exon 10/3'-UTR. VS was determined by amplification of exon 5 of RHCE, and sequencing of PCR products was used to analyze C733G (Leu245Val). Twenty-two (11\%) of the

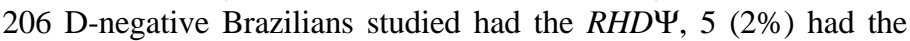
$R H D-C E-D^{s}$ hybrid gene associated with the VS+V-phenotype, and $179(87 \%)$ entirely lacked $R H D$. As expected, $R H D$ was deleted in all the 50 individuals of Caucasian descent. Among the 156 individuals of African descent, $22(14 \%)$ had inactive RHD and 3\% had the RHD$C E-D^{s}$ hybrid gene. These data confirm that the inclusion of two different multiplex PCR for $R H D$ is essential to test the D-negative Brazilian population in order to avoid false-positive typing of polytransfused patients and fetuses.

\section{Introduction}

The $\mathrm{Rh}$ blood group system is clinically important because it is involved in hemolytic disease of the newborn, hemolytic transfusion reactions and autoimmune hemolytic anemia. $\mathrm{Rh}$ is a highly complex red cell blood group system with 46 antigens $(1,2)$.
Key words

- RHD pseudogene

- RHD-CE-D ${ }^{s}$

- D-negative phenotype

- VS antigen

- Brazilians
The most important antigens are D, C/c, and E/e. The Rh system antigens are encoded by two homologous genes (3), the RHD gene and the RHCE gene, both located on chromosome 1p34.3-p36.1 (4). RHCE gives rise to $\mathrm{C} / \mathrm{c}$ and $\mathrm{E} / \mathrm{e}$ polymorphism and $R H D$ encodes the RhD antigen (5).

Total or partial deletion of the RHD gene 
can result in the D-negative phenotype (3,69). In non-Whites, D-negativity can appear in individuals carrying the complete $R H D$ gene $(10,11)$. This group includes individuals of black or Asian origin $(10,11)$ who exhibit either an internal duplication (12) or a deletion (13) within the RHD gene, resulting in a premature stop codon in $R H D$ transcripts. The presence of certain $R H D$ regions in hybrid genes encoding partial D antigens may predict a $\mathrm{D}$-negative phenotype, and the presence of some $R H D$ regions in genes encoding no $\mathrm{D}$ antigen may predict a Dpositive phenotype. In order to avoid these complications, methods which detect more than one region of $R H D$ have been introduced $(11,14,15)$.

About two-thirds of D-negative Africans have an inactive $R H D$ gene (12). This pseudogene $(R H D \Psi)$ has a 37-bp insert in exon 4 , which may introduce a reading frame shift and premature termination of translation and a translation stop codon in exon 6 (12). Of the remaining one-third of African D-negative donors, about half appear to be homozygous for an $R H D$ deletion and about half have the $R H D-C E-D^{s}$ hybrid gene characteristic of the $(C) c e^{s}$ haplotype that produces c, VS, and abnormal $\mathrm{C}$ and $\mathrm{E}$, but not D $(8,12)$. In D-negative African Americans and South African people of mixed race, the same three genetic backgrounds are present, but $24 \%$ of African Americans and $17 \%$ of South African donors of mixed race have RHD $\Psi$, and $54 \%$ of African Americans and $81 \%$ of South African donors of mixed race have no $R H D$ (12).

In the present study we investigated whether D-negative Brazilian blood donors of heterogeneous ethnic origin had altered RHD. We studied DNA samples from 206 D-negative blood donors (50 of Caucasian descent and 156 of African descent) by two different multiplex PCR that detect $R H D, D$ variants, $R H C / c$ and the $R H D \Psi$ and by sequencing exon 5 of $R H C E$ for the $733 \mathrm{C}>\mathrm{G}$ polymorphism (VS antigen). Our observa- tion was in agreement with previous publications showing that $R H D$ was deleted in all individuals of Caucasian descent. However, $14 \%$ of D-negative Brazilians of African descent studied had the RHD $\Psi$ and $3 \%$ had the $R H D-C E-D^{s}$ hybrid gene. These data show the necessity of performing multiplex PCR for detecting more than one region of RHD and the 37-bp insertion in populations of African descent for predicting the D phenotype from DNA in order to avoid falsepositive typing of polytransfused patients and fetuses.

\section{Material and Methods}

\section{Blood donors}

We studied peripheral blood samples from 206 random D-negative blood donors (50 of Caucasian descent and 156 of African descent) who agreed to participate in this study by signing an informed consent form. The study was approved by the Medical Ethics Committee of UNICAMP and CONEP.

\section{Agglutination tests}

$\mathrm{RhD}$ phenotypes were determined by hemagglutination in gel cards (Diamed AG, Morat, Switzerland) using two different commercial sources of monoclonal antisera (Gamma Biologicals Inc., Houston, TX, USA; Diamed AG). VS and V phenotypes were determined by standard techniques using polyclonal antibodies (patient serum).

\section{DNA preparation}

DNA was extracted from blood samples using the DNAzol (Gibco BRL, Rockville, MD, USA) and a blood DNA purification kit (Amersham Pharmacia Biotech Inc., Piscataway, NJ, USA) according to manufacturer recommendations.

Allele-specific PCR for RHD genotypingPCR analysis for the presence of $R H D$ was 
performed in two genomic regions, intron 4 and exon 10. Briefly, PCR was performed with 100-200 ng of DNA, 50 pmol of each primer, $2 \mathrm{nmol}$ of each dNTP, $1.0 \mathrm{U}$ Taq DNA polymerase, and buffer in a final volume of $50 \mu \mathrm{l}$. PCR was carried out in a thermal cycler (9700, Perkin Elmer, Foster City, CA, USA) and the same profile was used for both assays, as follows: $15 \mathrm{~min}$ at $95^{\circ} \mathrm{C}, 35$ cycles of $40 \mathrm{~s}$ at $94^{\circ} \mathrm{C}, 40 \mathrm{~s}$ at $62^{\circ} \mathrm{C}$, and $1 \mathrm{~min}$ at $72^{\circ} \mathrm{C}$, followed by $10 \mathrm{~min}$ at $72^{\circ} \mathrm{C}$. Amplified products were analyzed by electrophoresis in $1.5 \%$ agarose gel in Trisacetate EDTA buffer. For exon 10, a common 5' primer $(\mathrm{EX10F})$ was used for both $R H D$ and $R H C E$. When paired with the RHDspecific 3'-untranslated region (UTR) primer, it produced a product of $210 \mathrm{bp}$, and when paired with the RHCE-specific 3'-UTR primer, a product of $163 \mathrm{bp}$ (16) was produced. A set of three primers, RHI41 and RHI42 (previously reported; 16), and an additional third primer RHI43 were used for intron 4. The combination of these three primers generates products of $115 \mathrm{bp}$ for RHD and $236 \mathrm{bp}$ for RHCE (Figure 1). The sequences of the primers are listed in Table 1.

\section{Multiplex PCR for the presence of the RHD pseudogene}

Analysis of the $R H D \Psi$ 37-bp insert was performed using a multiplex PCR that detects the presence of $\mathrm{D}$, differentiates $R H C / c$ and identifies $R H D \Psi$ (12). PCR primers are listed in Table 2 . Thirty cycles of PCR were performed at $94^{\circ} \mathrm{C}$ for $1 \mathrm{~min}, 65^{\circ} \mathrm{C}$ for $1 \mathrm{~min}$, and $72^{\circ} \mathrm{C}$ for $3 \mathrm{~min} 30 \mathrm{~s}$. PCR products were analyzed by $2 \%$ agarose gel electrophoresis (Figure 2B).

\section{Multiplex PCR for RHD variants}

Analysis of $R H D$ variants was performed in all samples using an $R H D$ multiplex assay directed at six regions of $R H D$ (exons 3-7 and exon 9), covering all exons with $R H D$ specific sequences in the coding regions (15). The multiplex PCR was performed in a thermal cycler (9700, Perkin Elmer) with the following cycle specifications: 32 cycles of $1 \mathrm{~min}$ at $95^{\circ} \mathrm{C}, 1 \mathrm{~min}$ at $55^{\circ} \mathrm{C}$ and $45 \mathrm{~s}$ at $72^{\circ} \mathrm{C}$, followed by $10 \mathrm{~min}$ at $72^{\circ} \mathrm{C}$. PCR products were size-separated by $8 \%$ acrylamide gel electrophoresis (Figure 2A). PCR primers are listed in Table 3.

\section{Sequence analysis}

Sequence analysis was performed on PCR products amplified from genomic DNA using $R H C E$-specific primers for exon 5 (Table 4) to determine the presence of $733 \mathrm{G}$ predicted to encode Val245 (VS+) and RHDspecific primers for exon 3 (Table 4) to determine the presence of the $D-C E$ hybrid. PCR products were purified on $1 \%$ agarose gels using a Qiaex II gel extraction kit (Qiagen, Valencia, CA, USA), and sequenced directly using an ABI 373XL Perkin Elmer Biosystems sequencer.

Table 1. Primers used for RHD genotyping.

\begin{tabular}{lll}
\hline Primers & Sequence & Intron/exon/bp \\
\hline RHI41 & 5'-GTG TCT GAA GCC CTT CCA TC-3' & Intron 4/236/115 \\
RHI42 & 5'-GAA ATC TGC ATA CCC CAG GC-3' & \\
RHI43 & 5'-ATT AGC TGG GCA TGG TGG TG-3' & \\
EX10F & 5'-TT CCT CAT TTG GCT GTT GGA TTT TAA-3' & Exon 10/210/163 \\
RHD3'-UTR & 5'-GTA TTC TAC AGT GCA TAA TAA ATG GTG-3' & \\
RHCE3'-UTR & 5'-CTG TCT CTG ACC TTG TTT CAT TAT AC-3' &
\end{tabular}

Table 2. Primers used for identification of RHD-CE-DS.

\begin{tabular}{lll}
\hline Primers & Sequence & Exon/bp \\
\hline Exon 7 for & 5'-AGC TCC ATC ATG GGC TAC AA-3' & Exon 7/95 \\
Exon 7 rev & 5'-ATT GCC GGC TCC GAC GGT ATC-3' & \\
Intron 3 for 1 & 5'-GGG TTG GCT GGG TAA GCT CT-3' $^{\prime}$ Intron 4/498 \\
Intron 4 rev & 5'-GAA CCT GCT CTG TGA AGT GCT-3' $^{\prime}$ ' & \\
Exon 4 insert & 5'-AAT AAA ACC AGT AAG TTC ATG TGG-3' & Exon 4 37-insert/250 \\
Intron 3 for 2 & 5'-AAC CTG GGA GGC AAA TGT T1-3' & \\
C for & 5'-CAG GGC CAC CAC CAT TTG AA-3' & Exon 2/320 \\
C rev & 5'-GAA CAT GCC ACT TCA CTC CAG-3' & \\
c for & 5'-TCG GCC AAG ATC TGA CCG-3' & Exon 2/177 \\
c rev & 5'-TGA TGA CCA CCT TCC CAG G-3' & \\
&
\end{tabular}




\section{Results}

\section{Serology}

Red blood cells from the 206 blood donors gave D-negative results with two

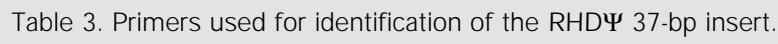

\begin{tabular}{lll}
\hline Primers & Sequence & Exon/bp \\
\hline MR364 & 5'-TCGGTGACTGATCTCAGTGGA-3' & Exon 3/111 \\
MR474M & 5'-ACTGATGACCATCCTCATGT-3' & \\
MR496 & 5'-CACATGAACATGATGCACA-3' & Exon 4/126 \\
MR621 & 5'-CAAACTGGGTATCGTTGCTG-3' & \\
M R648 & 5'-GTGGATGTTCTGGCCAAGTT-3' & Exon 5/157 \\
Mrex5 & 5'-CACCTTGCTGATCTTACC-3' & \\
M R898 & 5'-GTGGCTGGGCTGATCTACG-3' & Exon 5/57 \\
Mrex6 & 5'-TGTCTAGTTCTTACCGGCAAGA-3' & \\
MR973 & 5'-AGCTCCATCATGGGCTACAA-3' & Exon 7/96 \\
MR1068 & 5'-ATTGCCGGCTCCGACGGTATC-3' & \\
Mre9SD2 & 5'-AACAGGTTGCTCCTAAATATT-3' & Exon 9/71 \\
MR1219 & 5'-AAACTTGGTCATCAAAATATTAACCT-3' &
\end{tabular}

Table 4. Primers used for sequence analysis of VS and D-CE hybrid.

\begin{tabular}{lll}
\hline Primers & Sequence & Exon/bp \\
\hline RHCEint4 sense & 5'-GAG GTT GCA GTG AGC CCA TGA TCG-3' & \multirow{2}{*}{ Exon 5/474 } \\
RHCEex5 reverse & 5'-TGA CCC TGA GAT GGC TGT CA-3' & \\
RHDex3 sense & 5'-TCG GTG CTG ATC TCA GTG GA-3' & Exon 3/116 \\
RHDex3 reverse & 5'-GAT ATT ACT GAT GAC CAT CCT-3' &
\end{tabular}

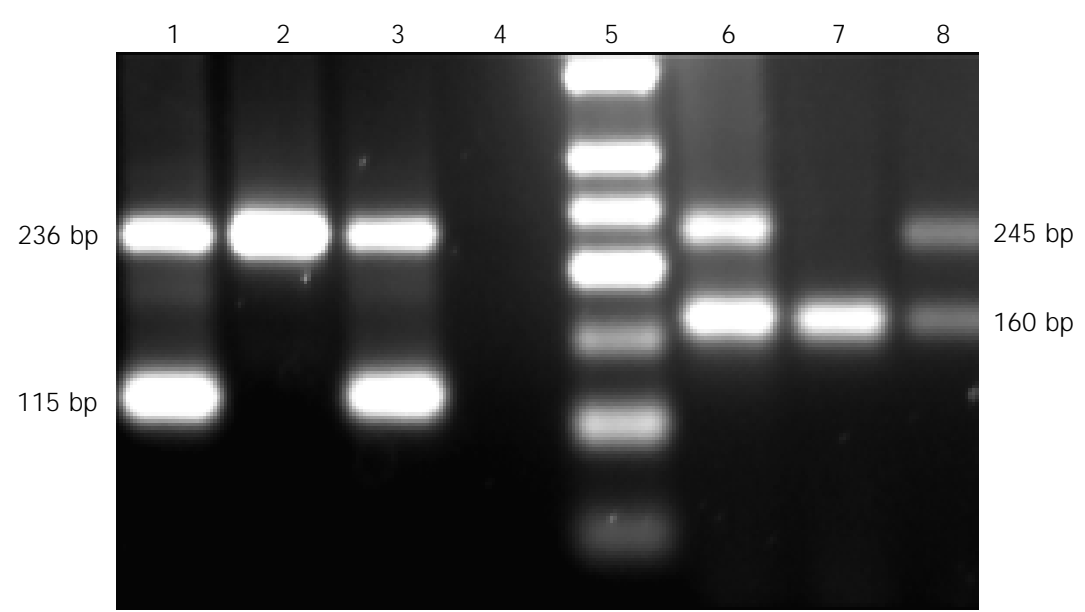

Figure 1. RHD genotyping by intron 4 and exon 10 of RHD. Lanes 1 and 3: RHD-positive samples display bands of $236 \mathrm{bp}$ for RHCE and $115 \mathrm{bp}$ for the RHD intron 4 sequence. Lane 2: RHD-negative sample displays only the 236-bp band corresponding to the RHCE intron 4 sequence. Lane 4: Reaction blank. Lane 5: 50-bp DNA ladder. Lanes 6 and 8: RHD-positive samples that amplify a 245-bp product of the RHD and a 160-bp product of the RHCE exon 10 sequence. Lane 7: RHD-negative sample displays only the 160-bp band corresponding to the RHCE exon 10 sequence.
alloanti-D reagents that react with all known partial D and weak D antigens. Red blood cells from five black donors who were Dnegative were phenotyped as $\mathrm{C}+\mathrm{c}+\mathrm{E}-\mathrm{e}+\mathrm{VS}+$ and $\mathrm{V}$-. These five donors all showed a weak expression of $\mathrm{C}$.

\section{Screening D-negative donors for exon 10 and intron 4}

All D-negative donors were tested by the allele-specific PCR method designed to determine the presence of $R H D$ exon 10 and intron 4 (Figure 1). Three patterns of reaction were apparent: presence of both $R H D$ regions, absence of both $R H D$ regions, and presence of $R H D$ exon 10, but absence of $R H D$ intron 4. Of the 206 D-negative Brazilian blood donors tested, $87 \%$ lacked $R H D$ (50 of Caucasian descent and 129 of African descent), $11 \%$ had both regions of $R H D$, and $2 \%$ had only $R H D$ exon 10 (Table 5).

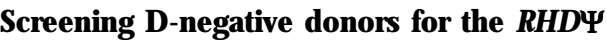 37-bp insert}

Of 156 D-negative samples from people of African origin, $22(14 \%)$ contained the exon 4/37-bp insert (Table 5, Figure 2B).

\section{Screening D-negative donors for RHD exons 3-7 and exon 9}

Multiplex PCR to detect D variants (Figure $2 \mathrm{~A}$ ) in selected donors with $R H D$ revealed that donors with $R H D$ exon 10 and intron 4 also had $R H D$ exons 3, 4, 5, 6, 7, and 9 , suggesting the presence of a grossly intact $R H D$. Red cells from five donors of African descent with $R H D$ exon 10, but without $R H D$ intron 4 , were $\mathrm{C}+$ and VS+V-. In addition to $R H D$ exon 10, donors of this type had $R H D$ exon 9 and a hybrid exon 3 comprising a $5^{\prime}$ end derived from $R H D$ and a 3 ' end derived from $R H C E$. The presence of the $773 \mathrm{G} \mathrm{mu-}$ tation in exon 5 of the RHCE determined by sequencing confirmed the VS antigenicity. 
This suggests that these five donors (2\%) have the RHD-CE-D gene associated with the $(C) c e^{s}$ complex $\left(R H D-C E-D^{s}\right)$ (Table 5).

Donors with neither exon 10 nor intron 4 of $R H D$ also lacked $R H D$ exons 3, 4, 5, 6, 7 and 9.

\section{Genomic DNA analysis by sequencing}

Genomic DNA analysis performed by sequencing revealed in five donors of African descent the presence of the $D$-CE hybrid exon 3 and the $733 \mathrm{G}$ mutation [predicted to encode Val245 (VS+)], associated with the $R H D-C E-D^{s}$ hybrid gene (Table 5).

\section{Discussion}

There are actually three genetic mechanisms associated with the D-negative phenotype: deletion of $R H D$ (3), an $R H D$ pseudogene containing a 37-bp insert and one or two stop codons (12), and a hybrid $R H D$ $C E-D^{\mathrm{s}}$ gene that probably produces an abnormal $\mathrm{C}$ antigen but does not produce a $\mathrm{D}$ antigen $(8,12) . R H D$ is generally absent in $R H D$-negative Caucasians carrying the cde haplotype. However, exceptions have been

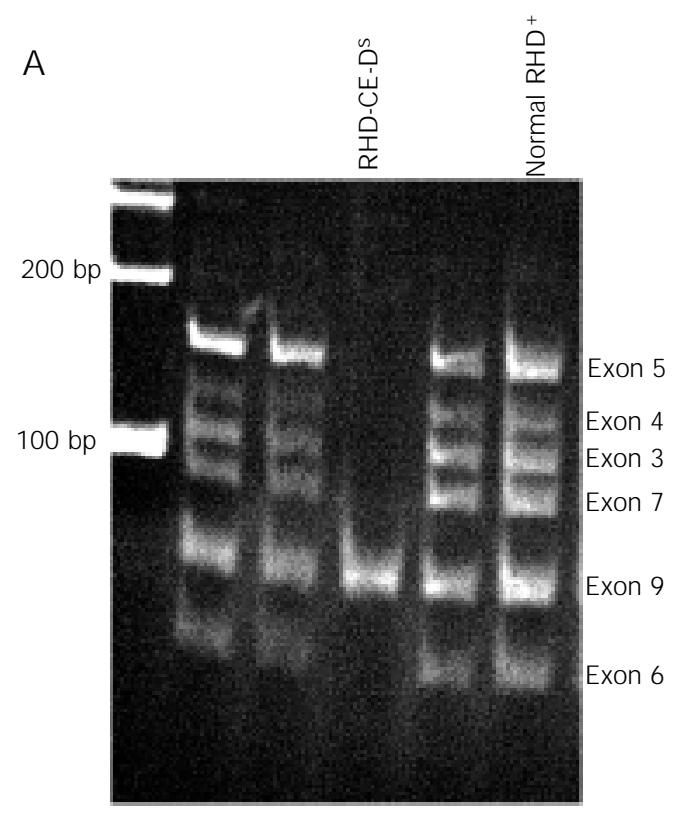

reported among Caucasians with the less frequent $\mathrm{Ce}$ and $\mathrm{cE}$ haplotypes and among D-negative individuals of African descent $(10,14,17,18)$. The $R H D \Psi$, characterized by an insertion of $37 \mathrm{bp}$ leading to a premature stop codon, can inadvertently cause discrepancy in genotype/phenotype correlation unless a specific assay (12) for detecting this insertion is employed. $R H D \Psi$ is found in Dnegative South Africans (66\%) and in African Americans (24\%) (12). In our study, $11 \%$ of the 206 D-negative Brazilians studied had this nonfunctional $R H D$.

An $R H D-C E-D$ fusion gene, in which the $3^{\prime}$ end of exon 3 plus exons 4-8 is derived from $R H C E$, is sometimes associated with a D-negative phenotype in people of African

Table 5. Results of testing for the presence or absence of RHD, RHD $\Psi$ and RHD-CE-Ds in 206 Brazilian blood donors.

\begin{tabular}{|c|c|c|c|c|}
\hline \multirow[t]{2}{*}{ Donors } & \multirow[t]{2}{*}{ Phenotype } & \multicolumn{3}{|c|}{ Genotype } \\
\hline & & RHD- & 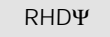 & RHD-CE-D ${ }^{S}$ \\
\hline Caucasian & RhD- & $50(100 \%)$ & 0 & 0 \\
\hline African & RhD- & $129(83 \%)$ & $22(14 \%)$ & $5(3 \%)$ \\
\hline Total & 206 & 179 (87\%) & $22(11 \%)$ & $5(2 \%)$ \\
\hline
\end{tabular}

B

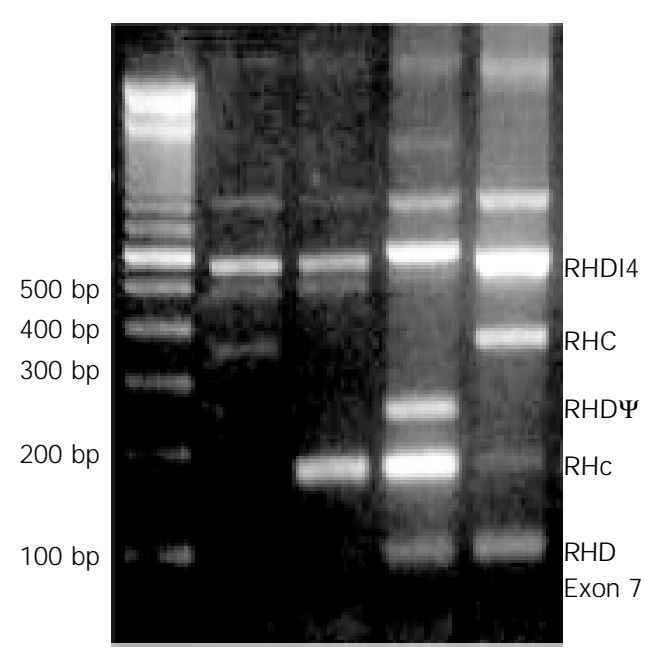

Figure 2. Multiplex PCR for detection of the RHD hybrid alleles and the RHDY. A, 8\% acrylamide gel showing results with multiplex PCR products amplified with six RHD-specific primer sets (exons 3, 4, 5, 6, 7 and 9 ). $B, 2 \%$ agarose gel showing results with multiplex PCR for predicting $\mathrm{D}$ and $\mathrm{C} / \mathrm{C}$ phenotype and for detecting the presence of RHDY. 
origin $(8,12)$. The hybrid gene carries a Leu245Val substitution responsible for the $\mathrm{VS}$ antigen and is associated with the presence of a weak $\mathrm{C}$. We found this hybrid gene in five donors of African descent phenotyped as $\mathrm{D}-\mathrm{C}^{\text {weak }} \mathrm{c}+\mathrm{E}-\mathrm{e}+\mathrm{VS}+\mathrm{V}$-. These samples were D-positive by exon 10 analysis but Dnegative by intron 4 and exon 7 analysis. The five samples were all heterozygous for $\mathrm{C} 733 \mathrm{G}$ in exon 5 of RHCE which predicts a Leu245Val (VS antigen) and so had a probable $c e /(C) c e^{s}$ genotype.

These findings, taken together with a previous report that $R H D \Psi$ is of high prevalence in populations of similar background (10), strongly suggest that genotype determination of $R H$ must include a thorough analysis of $R H D$. In the present study, we used two multiplex PCR, one (15) to detect gross chromosomal alterations in RHD and RHCE including gene rearrangement and hybrid genes, and the other (12) to detect $R H D \Psi$. Furthermore, the multiplex PCR that detects $R H D \Psi$ has the advantage of determining $\mathrm{C} / \mathrm{c}$ at the DNA level in the presence of $R H D$, a feature that is desired in transfusion practice and to predict the $\mathrm{RhD}$ blood type of a fetus in populations of African descent. Typing the fetus for the $R H C$ allele is also valuable because anti-G may be responsible for hemolytic disease of the newborn.

The most common D-negative Rh haplotype in Africans is $R H D \Psi$ with the ce allele of RHCE. The 37-bp insert in exon 4 of
$R H D \Psi$ is a duplication of a sequence spanning the boundary of intron 3 and exon 4 . This insert may introduce a reading frame shift and a translation stop codon at position 210. However, the duplication introduces another potential splice site at the $3^{\prime}$ end of the inserted intronic sequence in exon 4 and another stop codon in exon 6 of the gene (12). RHD mRNA was not detected in Dnegative individuals with $R H D \Psi$, despite the presence of $R H C E$ transcripts. In fact, Africans with $R H D \Psi$ are truly D-negative since they can produce anti-D and cause hemolytic disease of the newborn as previously reported (12).

Our results confirm the necessity to perform multiplex PCR including gene rearrangement and hybrid genes and the RHD $\Psi$ in populations of African descent for the appropriate management of transfused patients and for RhD-negative pregnant women who are sensitized, particularly when the fetal $R H D$ is determined by molecular assays.

Finally, the $11 \%$ prevalence of $R H D \Psi$ suggests a high degree of admixture of individuals of African descent in the Brazilian population.

\section{Acknowledgments}

We thank Maria Helena M. Carvalho for technical assistance.

\section{References}

1. Issitt PD (1994). The Rh blood group system: additional complexities (Editorial). Immunohematology, 10: 109-116.

2. Daniels GI, Anstee DJ, Cartron J P, Dahr W, Fletcher A, Garratty G, Henry S, J orgensen J , J udd WJ , Komstad L, Levene C, Lin M, Lomas-Francis C, Lubenko A, Moulds JJ, Moulds J M, Overbeeke M, Reid ME, Rouger $P$, Scott $M$, Sistonen $P$, Smart E, Tani $Y$, Wendel $S \&$ Zelinski T (2001). International Society of Blood Transfusion Working Party on terminol- ogy for red cell surface antigens. Vox Sanguinis, 80: 193-196.

3. Colin Y, Cherif-Zahar B, Le Van Kim C, van Huffel R \& Cartron JP (1991). Genetic basis of the RhD-positive and RhD-negative blood group polymorphism as determined by Southem analysis. Blood, 78: 2747-2752.

4. Cherif-Zahar B, Mattei MG, Le Van Kim C, Bailly P \& Cartron J P (1991). Localization of the human Rh blood group gene structure to chromosome region 1p34.3- 1p36.1 by in situ hybridization. Human Genetics, 86: 398-400.

5. Simsek $S$, J ong CAM, Cuijpers HTM, Bleeker PMM, Westers TM, Overbeeke MAM, Goldschmeding R, van der Schoot CE \& von dem Bome AEG (1994). Sequence analysis of cDNA derived from reticulocyte mRNAs coding for Rh polypeptides and demonstration of E/e and C/ c polymorphisms. Vox Sanguinis, 67: 203209.

6. Hyland CA, Wolter LC \& Saul A (1994). 
Three unrelated RhD gene polymorphisms identified among blood donors with Rhesus CCee $\left(r^{\prime} r^{\prime}\right)$ phenotypes. Blood, 84: 321-324.

7. Umenishi F, Kajii E \& Ikemoto S (1994). Molecular analysis of $\mathrm{Rh}$ polypeptides in a family with RhD positive and RhD negative phenotypes. Biochemical J ournal, 299: 207-211.

8. Faas BHW, Beckers EAM, Wildoer P, Lightart PC, Overbeeke MAM, Zondervan HÁ, von dem Borne AEGKr \& van der Schoot CE (1997). Molecular background of VS and weak $C$ expression in blacks. Transfusion, 37: 38-44.

9. Blunt T, Daniels G \& Carrit B (1994). Serotype switching in a partially detected RHD gene. Vox Sanguinis, 67: 397-401.

10. Daniels G, Green C \& Smart E (1997). Differences between RhD-negative Africans and RhD-negative Europeans. Lancet, 380: 862-863.

11. Okuda H, Kawano M, Iwamoto S, Tanaka M, Seno T, Okubo Y \& Kajii E (1997). The
RHD gene is highly detectable in RhDnegative J apanese donors. J ournal of Clinical Investigation, 100: 373-379.

12. Singleton BK, Green CA, Avent ND, Martin PG, Smart E, Daka A, Narter-Olaga EG, Hawthome LM \& Daniels G (2000). The presence of an RHD pseudogene containing a 37 base pair duplication and a nonsense mutation in Africans with the Rh Dnegative blood group phenotype. Blood, 95: 12-18.

13. Chang J G, Wang J C, Yang TY, Tsan KW, Shih MC, Peng CT \& Tsai CH (1998). Human Del is caused by a deletion of 1,013 bp between intron 8 and 9 including exon 9 of RHD gene. Blood, 92: 2602-2604.

14. Avent ND, Martin PG, Armstrong-Fisher SS, Liu W, Finning KM, Maddocks D \& Urbaniak J (1997). Evidence of genetic diversity underlying $R h D^{-}$, weak $D\left(D^{\mathrm{u}}\right)$, and partial $D$ phenotypes as determined by multiplex polymerase chain reaction analysis of the RHD gene. Blood, 89: 2568-2577.
15. Maaskant-van Wijk PA, Faas $B H$, de Ruijter J A, Overbeeke MA, von dem Borne $A E$, van Rhenen $D J$ \& van der Schoot CE (1998). Genotyping of RHD by multiplex polymerase chain reaction analysis of six RHD-specific exons. Transfusion, 38: 1015-1021.

16. Reid ME, Rios M, Powell D, Charles-Pierre D \& Malavade V (2000). DNA from blood samples can be used to genotype patients who have recently received a transfusion. Transfusion, 40: 48-53.

17. Huang $\mathrm{CH}$ (1996). Alteration of RH gene structure and expression in human dCCee and DCW-red blood cells: phenotypic homozygosity versus genotypic heterozygosity. Blood, 88: 2326-2333.

18. Andrews KT, Wolter LC, Saul A \& Hyland CA (1998). The $\mathrm{RhD}^{-}$trait in a white patient with the RhCCee phenotype attributed to a four-nucleotide deletion in the RHD gene. Blood, 92: 1839-1840. 